\title{
Effect of Chitosan on Gastrointestinal Absorption of Water-Insoluble Drugs Following Oral Administration in Rats
}

\author{
Masayuki NAdAi ${ }^{a}$ Chiharu TAJIRI, ${ }^{a}$ Hideo YoshizUmi, ${ }^{a}$ Yuji SuzUKI,${ }^{b}$ Ying Lan ZhaO, ${ }^{b, c}$ \\ Masao Kimura, ${ }^{b}$ Yoshimi TsuneKawa, ${ }^{b, d}$ and Takaaki HaSEGAWA ${ }^{*, b}$ \\ ${ }^{a}$ Department of Pharmaceutics, Faculty of Pharmacy, Meijo University; 150 Yagotoyama, Tenpaku-ku, Nagoya 468-8503, \\ Japan: ${ }^{b}$ Department of Pharmacy and Pharmacokinetics, Aichi Medical University School of Medicine; 21 Nagakute-cho, \\ Aichi-gun, Aichi 480-1195, Japan: ${ }^{c}$ National Chengdu Center for Safety Evaluation of Traditional Chinese Medicine, West \\ China Hospital, Sichuan University; Chengdu 610041, China: and ${ }^{d}$ Department of Pharmaceutics, School of Pharmacy, \\ Aichi Gakuin University; 1-100 Kusumoto-cho, Chikusa-ku, Nagoya 462-8650, Japan. \\ Received June 1, 2006; accepted July 6, 2006; published online July 7, 2006
}

Chitosan is widely used as a dietary weight-loss supplement in Japan. In the present study, we examined the effect of chitosan on the gastrointestinal absorption profiles of the water-insoluble drugs, indomethacin and griseofulvin, and the water-soluble drugs, acetaminophen and cephalexin, after oral administration in rats. Rats received oral administration of chitosan $(5 \mathrm{mg} / \mathrm{kg}$ or $25 \mathrm{mg} / \mathrm{kg})$ dissolved in $5 \%$ acetic acid or vehicle $15 \mathrm{~min}$ before oral administration of each drug. Chitosan at a dose of $25 \mathrm{mg} / \mathrm{kg}$, but not $5 \mathrm{mg} / \mathrm{kg}$, significantly decreased the plasma concentrations of indomethacin and griseofulvin after administration as a suspension with a significant delay of the time to reach maximum concentration compared to the corresponding control values (vehiclepretreated rats). However, pretreatment of chitosan $(25 \mathrm{mg} / \mathrm{kg})$ did not change the pharmacokinetics of indomethacin administered as a solution. Further, the same dose of chitosan had no effect on the pharmacokinetics of acetaminophen. The gastrointestinal absorption profile of an amino- $\beta$-lactam antibiotic, cephalexin, which is actively absorbed via carrier-mediated transport system, was also unchanged. The present findings at least suggest the possibility that chitosan at high dose reduces the gastrointestinal absorption of water-insoluble drugs such as indomethacin and griseofulvin, but not water-soluble drugs, by diminishing the surfactant-like effect of bile acids.

Key words chitosan; gastrointestinal absorption; bile acid; water-insoluble drug

Chitosan is an aminopolysaccharide derived from chitin, which has been found in the exoskeleton of arthropods (shrimp and crab shells) and certain fungi, ${ }^{1)}$ and is widely used as a dietary weight-loss supplement in Japan. Chitosan, which possesses cationic tertiary amino group $\left(-\mathrm{NH}_{3}^{+}\right)$in the molecule, reduces the absorption of fat from gastrointestinal tract by binding to anionic carboxyl groups of fatty acid and bile acids, and interferes with emulsification of neutral lipids such as cholesterol and other sterols., ${ }^{2,3)}$ Chitosan is also known to inhibit the absorption and enterohepatic circulation of bile acids, leading to the decrease of plasma cholesterol levels accompanied by an increase in compensatory oxidative synthesis of the bile acids from hepatic cholesterol.,5)

However, cholestylamine, a commercial available anion exchange resin to decrease plasma cholesterol levels, is well known to decrease the gastrointestinal absorption of various coadministered anionic drugs such as aspirin, phenylbutazone and warfarin by binding them to cholestylamine. ${ }^{6,7)}$ Therefore, there is a possibility that chitosan affects the gastrointestinal absorption of coadministered drugs in the same manner as cholestylamine. It is also reported that chitosan modifies the micelle formation by binding to bile acids, ${ }^{8)}$ leading to the reduction of the surfactant-like effect of bile acids in the dissolution process of water-insoluble drugs. ${ }^{9-11)}$ However, viscosity is a factor influencing the gastric emptying, one of the most important factors in determining the gastrointestinal absorption process of drugs, such as stomach content volume, $\mathrm{pH}$, osmolarity and temperature of the drug solution. ${ }^{12,13)}$ It is well known that chitosan solution exhibits a substantial viscosity, although it is unlikely that the cholesterol-lowering effect of chitosan is based on its high viscosity since chitosan does not increase intestinal content's supernatant viscosity. ${ }^{14,15)}$ Therefore, it might interact with coadministered drugs in the absorption process and change their effectiveness or safety.

The present study aims to clarify the effect of chitosan on the gastrointestinal absorption of drugs by evaluating alterations in plasma concentration-time profiles after oral administration of the water-insoluble drugs, indomethacin and griseofulvin, and the water-soluble drugs, acetaminophen and cephalexin, in rats.

\section{MATERIALS AND METHODS}

Chemicals Chitosan was obtained from Seikagaku Corporation (Tokyo, Japan). Indomethacin, acetaminophen and flufenamic acid were purchased from Sigma Chemical Co. (St. Louis, MO, U.S.A.). Griseofulvin and cephalexin were obtained from Wako Pure Chemical Industries, Ltd. (Osaka, Japan). Lorazepam was kindly supplied by the Sawai Pharmaceutical Company (Osaka, Japan). 3-Buthylxanthine, used as an internal standard for determining the concentration of cephalexin in plasma, was synthesized in our laboratory and was identical to that previously described. ${ }^{16-18)}$ All other reagents were obtained commercially and of the highest purity available.

Chitosan was dissolved in 5\% acetic acid solution at concentrations of 2.5 and $12.5 \mathrm{mg} / \mathrm{ml}$. Indomethacin and griseofulvin were suspended in $0.5 \%$ carboxymethylcellulose sodium salt at concentrations of 5 and $25 \mathrm{mg} / \mathrm{ml}$, respectively. For oral administration of indomethacin as a solution, indomethacin was dissolved to $5 \mathrm{mg} / \mathrm{ml}$ with $1 \%$ polyoxyeth- 
ylene (20) sorbitan monooleate (Tween 80) solution. Other drugs were used as aqueous solution $(15 \mathrm{mg} / \mathrm{ml}$ for acetaminophen, $5 \mathrm{mg} / \mathrm{ml}$ for cephalexin).

Animals Eight-to-nine-week-old male Wistar rats were purchased from SLC Japan (Hamamatsu, Japan). The body weight of the rats was standardized $(270-300 \mathrm{~g})$. The animals were housed under controlled environmental conditions (temperature $24-25^{\circ} \mathrm{C}$ and humidity $55 \pm 5 \%$ ) with a commercial food diet and water freely available. All animal experiments were carried out according to the Guidelines of the Faculty of Pharmacy, Meijo University for the Care and Use of Laboratory Animals.

Experimental Protocols One day before examination, rats under anesthesia by intraperitoneal injection of sodium pentobarbital $(25 \mathrm{mg} / \mathrm{kg})$ were cannulated with polyethylene tubes into the right jugular vein for blood sampling. The rats, fasted for $16 \mathrm{~h}$ before the experiments, received an oral administration of chitosan solution at doses of 5 or $25 \mathrm{mg} / \mathrm{kg}$ $(2 \mathrm{ml} / \mathrm{kg}$ ) dissolved in 5\% acetic acid solution (chitosan-pretreated group) or $5 \%$ acetic acid solution (vehicle-pretreated group). Fifteen minutes after administration of chitosan or vehicle, each drug solution or suspension $(2 \mathrm{ml} / \mathrm{kg})$ was administered orally. The dose of each drug used in this study was $10 \mathrm{mg} / \mathrm{kg}$ for indomethacin, $50 \mathrm{mg} / \mathrm{kg}$ for griseofulvin, $30 \mathrm{mg} / \mathrm{kg}$ for acetaminophen, and $10 \mathrm{mg} / \mathrm{kg}$ for cephalexin. Blood samples $(0.2 \mathrm{ml})$ were collected at designated intervals $(10,20,30,45,60,90,120,180,240,300,360,420,480$, 540 and $600 \mathrm{~min}$ after the oral administration of drug). Plasma samples were obtained by centrifugation of blood samples at $4000 \times \boldsymbol{g}$ for $10 \mathrm{~min}$ at $4^{\circ} \mathrm{C}$. Plasma samples were stored at $-30{ }^{\circ} \mathrm{C}$ until analysis.

Drug Analysis Concentrations of indomethacin, griseofulvin, acetaminophen and cephalexin in plasma were determined by HPLC. The apparatus used for HPLC was a Shimadzu LC-10A system (Kyoto, Japan) equipped with a UV detector (SPD-10 AV) consisting of an LC-10A liquid pump and an SIL-10A autoinjector. The column used for analysis of indomethacin, griseofulvin, acetaminophen and cephalexin was a Cosmosil 5C18-MS-II (4.6 by $150 \mathrm{~mm}$, Nacalai Tesque, Inc., Kyoto, Japan).

For measurement of the indomethacin concentration in plasma, $200 \mu \mathrm{l}$ of acetonitrile containing flufenamic acid $(2 \mu \mathrm{g} / \mathrm{ml})$ as an internal standard and $50 \mu \mathrm{l}$ of plasma samples were mixed. After centrifugation at $6000 \times \boldsymbol{g}$ for $10 \mathrm{~min}$, $80 \mu \mathrm{l}$ of the supernatant was injected into the HPLC system. The UV detector was set at $274 \mathrm{~nm}$, and the column temperature was $45^{\circ} \mathrm{C}$. The mobile phase was $30 \mathrm{~mm} \mathrm{KH}_{2} \mathrm{PO}_{4}$ buffer $(\mathrm{pH} 4.0)$ and acetonitrile $(1: 1, \mathrm{v} / \mathrm{v})$ solution, and the flow rate was $1.5 \mathrm{ml} / \mathrm{min}$.

Concentrations of griseofulvin in plasma were determined according to the reported procedure with some modifications. ${ }^{19)}$ Briefly, $250 \mu \mathrm{l}$ of methanol containing lorazepam $(8 \mu \mathrm{g} / \mathrm{ml})$ as an internal standard was added to $50 \mu \mathrm{l}$ of each sample and mixed. After centrifugation at $6000 \times \boldsymbol{g}$ for $10 \mathrm{~min}$, the resulting supernatant $(200 \mu \mathrm{l})$ was evaporated to dryness under a nitrogen gas stream at $50{ }^{\circ} \mathrm{C}$. The residue was reconstituted with $200 \mu \mathrm{l}$ of the mobile phase and injected into the HPLC system. The conditions were as follows: mobile phase, $30 \mathrm{~mm} \mathrm{KH}_{2} \mathrm{PO}_{4}$ buffer (pH 5.0)methanol $(1: 1, \mathrm{v} / \mathrm{v})$ solution; flow rate, $1.5 \mathrm{ml} / \mathrm{min}$; UV detector, $290 \mathrm{~nm}$; and column temperature, $40^{\circ} \mathrm{C}$.
Determination of concentrations of acetaminophen in plasma was carried out based on the reported methods with some modifications. ${ }^{20,21)}$ Briefly, each plasma sample $(50 \mu \mathrm{l})$ and $6 \%$ perchloric acid $(100 \mu \mathrm{l})$ containing 3-methylxanthine $(2 \mu \mathrm{g} / \mathrm{ml})$ as an internal standard were mixed. After centrifugation at $6000 \times \boldsymbol{g}$ for $10 \mathrm{~min}$, the resulting supernatant (50 $\mu \mathrm{l})$ was injected into the HPLC system. The UV detector was set at $274 \mathrm{~nm}$, and the column was heated to $45^{\circ} \mathrm{C}$. The mobile phase was $30 \mathrm{~mm} \mathrm{KH}_{2} \mathrm{PO}_{4}$ buffer $(\mathrm{pH} \mathrm{4.0)-acetonitrile}$ $(95: 5, \mathrm{v} / \mathrm{v})$ solution, and the flow rate was $0.9 \mathrm{ml} / \mathrm{min}$.

Concentration of cephalexin in plasma was measured as follows. Fifty microliters of each plasma sample and $50 \mu \mathrm{l}$ of $\mathrm{pH} 7.4$ McIlvaine buffer containing 3-buthylxanthine $(1 \mu \mathrm{g} / \mathrm{ml})$ as an internal standard and $50 \mu \mathrm{l}$ of $10 \%$ perchloric acid were mixed. After centrifugation at $6000 \times \boldsymbol{g}$ for $10 \mathrm{~min}$, the resulting supernatant $(120 \mu \mathrm{l})$ was mixed with $50 \mu \mathrm{l}$ of $5 \mathrm{~m}$ sodium acetate solution, and the mixture $(120 \mu \mathrm{l})$ was injected into the column. The mobile phase was $30 \mathrm{~mm}$ $\mathrm{KH}_{2} \mathrm{PO}_{4}$ buffer ( $\left.\mathrm{pH} 7.0\right)$-methanol $(80: 20$, v/v) solution, and the flow rate was $1.5 \mathrm{ml} / \mathrm{min}$. The UV detector was set at $274 \mathrm{~nm}$ and the column was heated to $42^{\circ} \mathrm{C}$.

For calculations of plasma drug concentrations, the standard curve for each drug was measured over an appropriate range and shown to be linear, and the within-day and between-day coefficients of variation for this assay were less than $7 \%$. No interference with the peaks of each drug was observed in any samples.

Data Analysis Concentration-time data for drugs in each rat were analyzed individually using a noncompartmental model. The maximum concentration $\left(C_{\max }\right)$ and the time to reach $C_{\max }\left(T_{\max }\right)$ were obtained from the observed data. When $C_{\max }$ and $T_{\max }$ could not be found during the experimental period of $600 \mathrm{~min}$ due to delay of gastrointestinal absorption of drug, these values at the last sampling point were used. The area under the curve $(A U C)$ was calculated by the trapezoidal rule for values up to the last measured concentration in plasma and was extrapolated to infinity by adding the following: the value of the last measured concentration in plasma divided by the terminal elimination rate constant, which was calculated by determining the slope of the leastsquares regression line from the terminal portion of the log concentration-time data. Systemic clearance $\left(C L_{\mathrm{SYS}} / F\right)$ was calculated as $C L_{\mathrm{SYS}} / F=\operatorname{dose} / A U C$, where $F$ represents the bioavailability of drug after oral administration. The mean residence time $(M R T)$ was calculated as $M R T=A U M C / A U C$, where $A U M C$ represents the area under the first moment of the curve. The steady-state volume of distribution $\left(V_{\mathrm{SS}} / F\right)$ was calculated as $V_{\mathrm{SS}} / F=C L_{\mathrm{SYS}} / F \times M R T$. However, in the experiments of oral administration of indomethacin and griseofulvin as the suspension, their pharmacokinetic parameters except for $C_{\max }, T_{\max }$ and $A U C$ up to the last measured concentration $\left(A U C_{0-600}\right)$ were not calculated, since enough plasma concentrations to calculate the elimination rate constant of these drugs were not obtained during the experimental period ( $0-600 \mathrm{~min})$.

Statistical Analysis All data are expressed as means \pm S.E.M. Statistical differences between the vehicle-pretreated group and chitosan-pretreated group were assessed by Student's $t$-test, and $p$ values less than 0.05 were taken as significant.

In the study using two different doses of chitosan $(5 \mathrm{mg} / \mathrm{kg}$ 
and $25 \mathrm{mg} / \mathrm{kg})$, statistical differences between the three groups (vehicle-, chitosan $(5 \mathrm{mg} / \mathrm{kg})$ - and chitosan $(25 \mathrm{mg} /$ $\mathrm{kg}$ )-pretreated groups) were assessed by one way analysis of variance, and statistical difference was defined as $p<0.05$ using Tukey's multiple comparison procedure.

\section{RESULTS}

Mean plasma concentration-time curves for indomethacin after a single oral administration as a suspension at a dose of $10 \mathrm{mg} / \mathrm{kg}$ in rats pretreated with vehicle or chitosan $(5 \mathrm{mg} / \mathrm{kg}$ or $25 \mathrm{mg} / \mathrm{kg}$ ) are shown in Fig. 1. Pretreatment with chitosan at a dose of $25 \mathrm{mg} / \mathrm{kg}$ dramatically delayed the elevation of plasma concentrations of indomethacin after oral administration compared with those in vehicle- and chitosan $(5 \mathrm{mg} / \mathrm{kg})$ pretreated rats. Plasma concentrations of indomethacin from 20 to $120 \mathrm{~min}$ after oral administration were significantly lower in chitosan $(25 \mathrm{mg} / \mathrm{kg})$-pretreated rats than those in vehicle- and chitosan $(5 \mathrm{mg} / \mathrm{kg})$-pretreated rats. As shown in Table 1, the $T_{\max }$ of indomethacin was significantly prolonged in rats pretreated with chitosan $(25 \mathrm{mg} / \mathrm{kg})$ compared to that in rats pretreated with vehicle. However, no significant differences in the $C_{\max }$ and $A U C_{0-600}$ of indomethacin were observed among these three groups.

Figure 2 shows the plasma concentration-time curves of indomethacin after oral administration as a solution dissolved in a small amount of polyoxyethylene (20) sorbitan monooleate in rats pretreated with vehicle or chitosan $(25 \mathrm{mg} / \mathrm{kg})$. Contrary to the results obtained after administra-

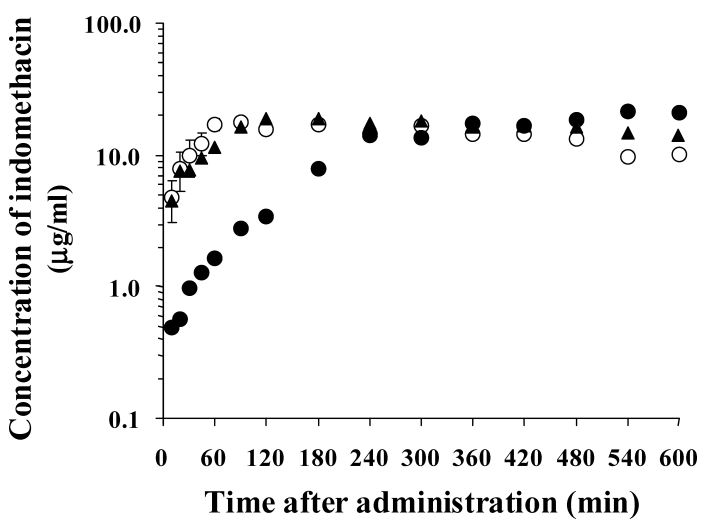

Fig. 1. Mean Plasma Concentration-Time Data for Indomethacin after Oral Administration of $10 \mathrm{mg} / \mathrm{kg}$ as Suspension in Rats Pretreated with Vehicle $(\bigcirc)$ or Chitosan $(\boldsymbol{\Delta} ; 5 \mathrm{mg} / \mathrm{kg} ; \boldsymbol{\bigcirc}, 25 \mathrm{mg} / \mathrm{kg})$

Each symbol represents mean \pm S.E.M. $(n=5)$. See Materials and Methods for details and drug administration. Values of plasma concentration of indomethacin at 20,30,45, $60,90,120,540$, and $600 \mathrm{~min}$ after administration of vehicle were significantly different from those after administration of chitosan $(25 \mathrm{mg} / \mathrm{kg})$. Values of plasma concentration of indomethacin at 20,30,45,90, and 120 min after administration of chitosan $(5 \mathrm{mg} / \mathrm{kg})$ were significantly different from those after administration of chitosan $(25 \mathrm{mg} / \mathrm{kg})$. tion of indomethacin as suspension, no significant differences in the plasma concentration-time curves of indomethacin after oral administration as a solution were observed between vehicle- and chitosan-pretreated rats. As summarized in Table 2, pretreatment with chitosan did not change any pharmacokinetic parameters of indomethacin.

Plasma concentration-time curves of griseofulvin after oral administration in rats pretreated with vehicle or chitosan $(25 \mathrm{mg} / \mathrm{kg})$ are illustrated in Fig. 3. The corresponding pharmacokinetic parameters of griseofulvin such as $T_{\max }, C_{\max }$ and $A U C_{0-600}$ are summarized in Table 3. As shown in Fig. 3 , pretreatment with chitosan $(25 \mathrm{mg} / \mathrm{kg})$ dramatically influenced the plasma concentration-time profile of griseofulvin. The plasma concentrations of griseofulvin till $240 \mathrm{~min}$ after administration were significantly lower in chitosan-pretreated rats than those in vehicle-treated rats. As shown in Table 3, pretreatment with chitosan significantly increased the $T_{\max }$ of griseofulvin, but decreased the $C_{\max }$ and $A U C_{0-600}$.

Table 1. Pharmacokinetic Parameters of Indomethacin after Oral Administration as Suspension in Rats Pretreated with Vehicle or Chitosan

\begin{tabular}{lccc}
\hline \hline Parameter & $C_{\max }(\mu \mathrm{g} / \mathrm{ml})$ & $T_{\max }(\min )$ & $A U C_{0-600}(\mu \mathrm{gh} / \mathrm{ml})$ \\
\hline Vehicle & $27.2 \pm 4.9$ & $192.0 \pm 51.6$ & $146.6 \pm 16.3$ \\
Chitosan & & & \\
$5 \mathrm{mg} / \mathrm{kg}$ & $26.1 \pm 1.9$ & $290.0 \pm 82.6$ & $158.4 \pm 16.8$ \\
$25 \mathrm{mg} / \mathrm{kg}$ & $33.3 \pm 3.4$ & $420.0 \pm 65.7^{a)}$ & $125.8 \pm 24.5$
\end{tabular}

Data represent the mean \pm S.E.M. $(n=5)$. Indomethacin $(10 \mathrm{mg} / \mathrm{kg})$ was administered orally $15 \mathrm{~min}$ after administration of vehicle or chitosan. $C_{\max }$, peak plasma concentration; $T_{\max }$, time to reach $C_{\max } ; A U C_{0-600}$, area under the plasma concentration-time curve from time zero to the last point $(600 \mathrm{~min}) . a$ ) Significantly different from vehicle $(p<0.05)$.

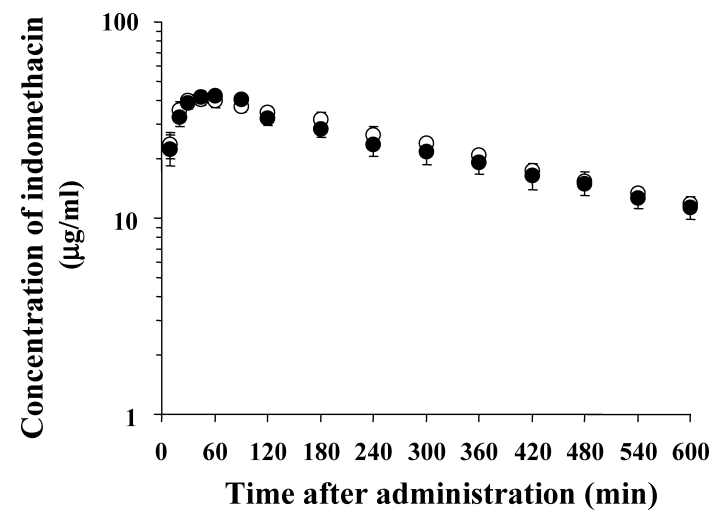

Fig. 2. Mean Plasma Concentration-Time Data for Indomethacin after Oral Administration of $10 \mathrm{mg} / \mathrm{kg}$ as an Aqueous Solution in Rats Pretreated with Vehicle $(\bigcirc)$ or Chitosan $(\mathbf{O})$

Each symbol represents the mean \pm S.E.M. $(n=5)$. See Materials and Methods for details and drug administration. No significant difference was observed between vehicle and chitosan $(25 \mathrm{mg} / \mathrm{kg})$

Table 2. Pharmacokinetic Parameters of Indomethacin after Oral Administration as Solution in Rats Pretreated with Vehicle or Chitosan

\begin{tabular}{lcccccc}
\hline \hline & $C_{\max }(\mu \mathrm{g} / \mathrm{ml})$ & $T_{\max }(\mathrm{min})$ & $A U C_{0-\infty}(\mu \mathrm{gh} / \mathrm{ml})$ & $M R T(\mathrm{~h})$ & $C L_{\mathrm{SYS}} / F(1 / \mathrm{h} / \mathrm{kg})$ & $V_{\mathrm{SS}} / F(1 / \mathrm{kg})$ \\
\hline Vehicle & $43.0 \pm 3.2$ & $40.0 \pm 6.1$ & $340 \pm 21$ & $8.09 \pm 0.84$ & $0.03 \pm 0.00$ & $0.24 \pm 0.03$ \\
Chitosan & $43.9 \pm 2.0$ & $50.0 \pm 6.1$ & $315 \pm 44$ & $7.22 \pm 0.64$ & $0.04 \pm 0.01$ & $0.24 \pm 0.01$
\end{tabular}

Data represent mean \pm S.E.M. $(n=5)$. Indomethacin $(10 \mathrm{mg} / \mathrm{kg})$ was administered orally $15 \mathrm{~min}$ after administration of vehicle or chitosan $(25 \mathrm{mg} / \mathrm{kg})$. $C_{\text {max }}$, peak plasma concentration; $T_{\max }$, time to reach $C_{\max } ; A U C_{0-\infty}$, area under the plasma concentration-time curve from time zero to infinity; $M R T$, mean residence time; $C L_{\mathrm{SYS}} / F$, systemic clearance; $V_{\mathrm{SS}} / F$, volume of distribution at steady-state; $F$, bioavailability; $k_{\mathrm{e}}$, first-order elimination rate constant. No significant differences in all parameters were observed between vehicle and chitosan. 
In the case of acetaminophen and cephalexin, pretreatment of chitosan did not induce any changes in the plasma concentration-time profiles of these drugs as illustrated in Figs. 4 and 5, respectively. As shown in Tables 4 and 5, no significant differences in the pharmacokinetic parameters of these drugs were observed between vehicle- and chitosan-pretreated rats.

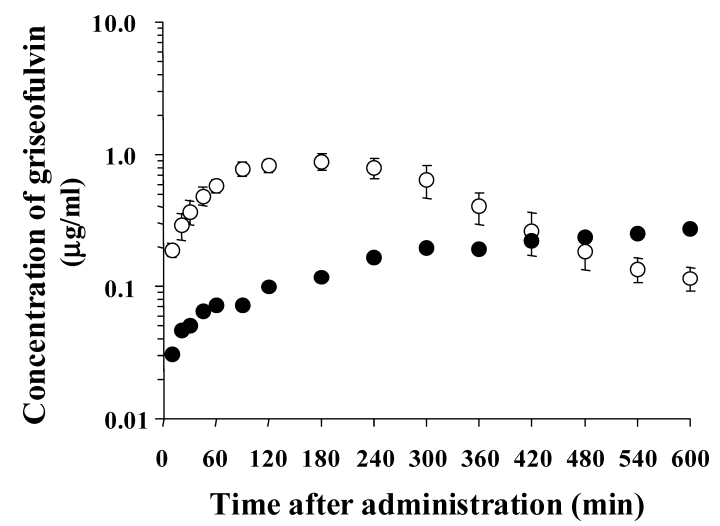

Fig. 3. Mean Plasma Concentration-Time Data for Griseofulvin after Oral Administration of $50 \mathrm{mg} / \mathrm{kg}$ in Rats Pretreated with Vehicle $(\bigcirc)$ or Chitosan (๑)

Each symbol represents the mean+S.E.M. $(n=5)$. See Materials and Methods for details and drug administration. Values of plasma concentration of griseofulvin at 10,20, $30,45,60,90,120,180$, and $240 \mathrm{~min}$ after administration of vehicle were significantly different from those after administration of chitosan $(25 \mathrm{mg} / \mathrm{kg})$.

Table 3. Pharmacokinetic Parameters of Griseofulvin after Oral Administration in Rats Pretreated with Vehicle or Chitosan

\begin{tabular}{llll}
\hline \hline & $C_{\max }(\mu \mathrm{g} / \mathrm{ml})$ & $T_{\max }(\min )$ & $A U C_{0-600}(\mu \mathrm{gh} / \mathrm{ml})$ \\
\hline Vehicle & $1.073 \pm 0.129$ & $157.5 \pm 40.6$ & $4.862 \pm 0.630$ \\
Chitosan & $\left.0.369 \pm 0.040^{a}\right)$ & $\left.432.0 \pm 81.4^{a}\right)$ & $1.638 \pm 0.289^{a)}$ \\
\hline
\end{tabular}

Data represent mean \pm S.E.M. $(n=5)$. Griseofulvin $(50 \mathrm{mg} / \mathrm{kg})$ was administered orally $15 \mathrm{~min}$ after administration of vehicle or chitosan $(25 \mathrm{mg} / \mathrm{kg}) . C_{\max }$, peak plasma concentration; $T_{\max }$, time to reach $C_{\max } ; A U C_{0-600}$, area under the plasma concentrationtime curve from time zero to the last point $(600 \mathrm{~min})$. a) Significantly different from vehicle $(p<0.05)$

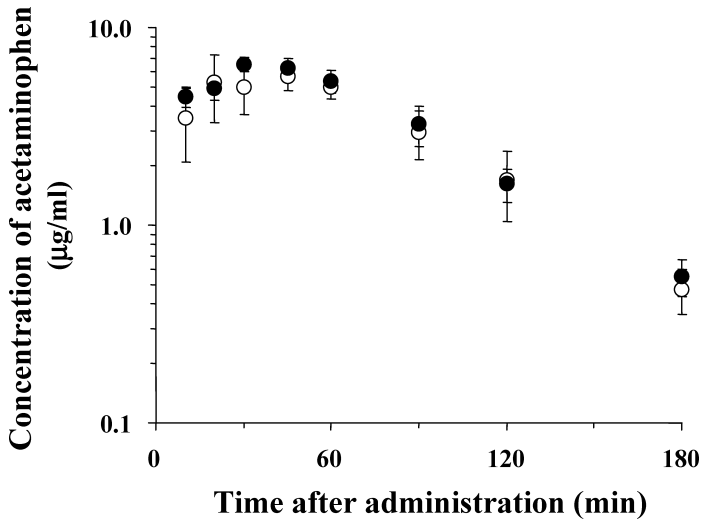

Fig. 4. Mean Plasma Concentration-Time Data for Acetaminophen after Oral Administration of $30 \mathrm{mg} / \mathrm{kg}$ in Rats Pretreated with Vehicle $(\bigcirc)$ or Chitosan (O)

Each symbol represents the mean \pm S.E.M. $(n=5)$. See Materials and Methods for details and drug administration. No significant difference was observed between vehicle and chitosan $(25 \mathrm{mg} / \mathrm{kg})$.

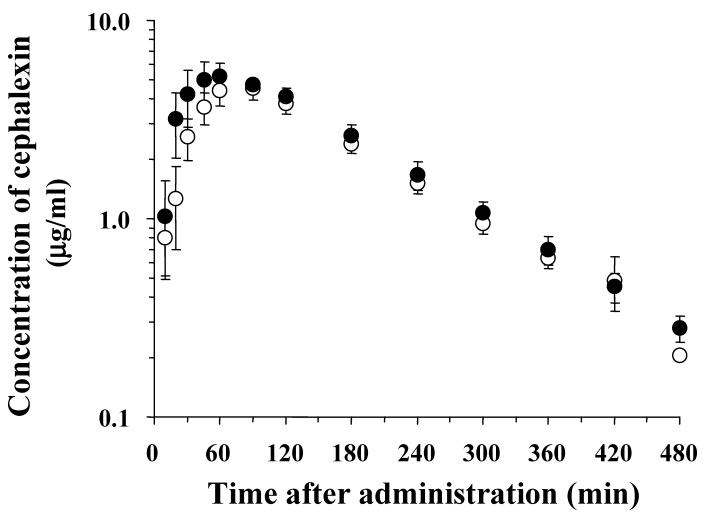

Fig. 5. Mean Plasma Concentration-Time Data for Cephalexin after Oral Administration of $10 \mathrm{mg} / \mathrm{kg}$ in Rats Pretreated with Vehicle $(\bigcirc)$ or Chitosan (O)

Each symbol represents mean \pm S.E.M. $(n=5)$. See Materials and Methods for details and drug administration. No significant difference was observed between vehicle and chitosan $(25 \mathrm{mg} / \mathrm{kg})$.

Table 4. Pharmacokinetic Parameters of Acetaminophen after Oral Administration in Rats Pretreated with Vehicle or Chitosan

\begin{tabular}{llllllll}
\hline \hline & $C_{\max }(\mu \mathrm{g} / \mathrm{ml})$ & $T_{\max }(\min )$ & $A U C_{0-\infty}(\mu \mathrm{gh} / \mathrm{ml})$ & $M R T(\mathrm{~h})$ & $C L_{\mathrm{SYS}} / F(1 / \mathrm{h} / \mathrm{kg})$ & $V_{\mathrm{SS}} / F(\mathrm{l} / \mathrm{kg})$ & $k_{\mathrm{e}}\left(\mathrm{h}^{-1}\right)$ \\
\hline Vehicle & $7.29 \pm 0.90$ & $37.5 \pm 13.2$ & $9.31 \pm 0.78$ & $1.23 \pm 0.14$ & $3.29 \pm 0.26$ & $4.02 \pm 0.55$ & $1.12 \pm 0.20$ \\
Chitosan & $7.59 \pm 0.37$ & $34.2 \pm 6.9$ & $10.42 \pm 1.02$ & $1.25 \pm 0.07$ & $3.02 \pm 0.30$ & $3.68 \pm 0.23$ & $0.98 \pm 0.09$
\end{tabular}

Data represent mean \pm S.E.M. $(n=5)$. Acetaminophen $(30 \mathrm{mg} / \mathrm{kg})$ was administered orally $15 \mathrm{~min}$ after administration of vehicle or chitosan $(25 \mathrm{mg} / \mathrm{kg})$. $C_{\mathrm{max}}$, peak plasma concentration; $T_{\mathrm{mx}}$, time to reach $C_{\mathrm{m}} ; A U C_{0}$, area under the plasma concentration-time curve from time zero to infinity; $M R T$, mean residence time; $C L_{\mathrm{SyS}} / F$, systemic clearance; $V_{\mathrm{SS}} / F$, volume of distribution at steady-state; $F$, bioavailability; $k_{\mathrm{e}}$, first-order elimination rate constant. No significant differences in all parameters were observed between vehicle and chitosan.

Table 5. Pharmacokinetic Parameters of Cephalexin after Oral Administration in Rats Pretreated with Vehicle or Chitosan

\begin{tabular}{lllllrr}
\hline \hline & $C_{\max }(\mu \mathrm{g} / \mathrm{ml})$ & $T_{\max }(\mathrm{min})$ & $A U C_{0-\infty}(\mu \mathrm{gh} / \mathrm{ml})$ & $M R T(\mathrm{~h})$ & $C L_{\mathrm{SYS}} / F(1 / \mathrm{h} / \mathrm{kg})$ & $V_{\mathrm{SS}} / F(\mathrm{l} / \mathrm{kg})$ \\
\hline Vehicle & $4.78 \pm 0.61$ & $78.0 \pm 7.3$ & $15.35 \pm 1.46$ & $2.93 \pm 0.25$ & $1.35 \pm 0.12$ \\
Chitosan & $6.03 \pm 0.71$ & $69.0 \pm 16.2$ & $17.46 \pm 1.43$ & $2.74 \pm 0.24$ & $1.18 \pm 0.10$ & $3.03 \pm 0.64$ \\
& & & & $0.44 \pm 0.03$ & $0.48 \pm 0.04$
\end{tabular}

Data represent mean \pm S.E.M. $(n=5)$. Cephalexin $(10 \mathrm{mg} / \mathrm{kg})$ was administered orally $15 \mathrm{~min}$ after administration of vehicle or chitosan $(25 \mathrm{mg} / \mathrm{kg}) . C_{\mathrm{max}}$, peak plasma concentration; $T_{\max }$, time to reach $C_{\max } ; A U C_{0 \_}$, area under the plasma concentration-time curve from time zero to infinity; $M R T$, mean residence time; $C L_{\mathrm{SYS}} / F$, systemic clearance; $V_{\mathrm{SS}} / F$, volume of distribution at steady-state; $k_{\mathrm{e}}$, first-order elimination rate constant. No significant differences in all parameters were observed between vehicle and chitosan. 


\section{DISCUSSION}

The current study clearly demonstrated that chitosan significantly changed the gastrointestinal absorption of indomethacin and griseofulvin by prolonging the $T_{\max }$ in rats, suggesting the possibility that chitosan interacts with waterinsoluble drugs such as indomethacin and griseofulvin.

It is reported that chitosan ( 3 to $6 \mathrm{~g} / \mathrm{d}$ ) increases the fecal excretion of the two bile acids, cholic acid and chenodeoxycholic acid, in male subjects ${ }^{22)}$ and that a microcrystalline chitosan $(2.4 \mathrm{~g} / \mathrm{d})$ tends to decrease the levels of low density lipoprotein in healthy obese women. ${ }^{23)}$ Coadministration of chitosan $(2.4 \mathrm{~g} / \mathrm{d})$ with glucomannan reduces serum cholesterol levels in overweight normocholesterolemic subjects, which is probably due to an increase in the fecal steroid excretion. ${ }^{24)}$ A most recent study showed that chitosan ( $\left.2.5 \mathrm{~g} / \mathrm{d}\right)$ significantly increased the fecal fat excretion in males, but not in females, although the fat trapping effect of chitosan was clinically insignificant. ${ }^{25)}$ The dose of chitosan used in this study was $5 \mathrm{mg} / \mathrm{kg}(0.25 \mathrm{~g} / 50 \mathrm{~kg})$ or $25 \mathrm{mg} / \mathrm{kg}(1.25 \mathrm{~g} /$ $50 \mathrm{~kg}$ ), which was relatively lower than doses in their studies. In addition, it is well known that variations in gastric and intestinal $\mathrm{pH}$ affect the dissolution rate of ionizable drugs. Therefore, the present study used vehicle-treated rats as control rats, since chitosan dissolved in 5\% acetic acid was administered in rats. Indeed, the $C_{\max }$ of indomethacin observed in rats pretreated with vehicle was lower than that in rats pretreated with saline in place of 5\% acetic acid (data not shown).

Results obtained from this study revealed that chitosan pretreatment significantly delayed the absorption of indomethacin, judged by the prolonged $T_{\max }$, compared to vehicle pretreatment. However, the $C_{\max }$ and $A U C_{0-600}$ of indomethacin in chitosan-pretreated rats were comparable to those in vehicle-pretreated rats. These results suggest that the possible mechanism for chitosan-induced changes in the plasma concentration-time profiles of indomethacin is due to decreases in the dissolution rate of the drugs or prolongation of gastric emptying, and that the amount of this drug absorbed is unchanged. However, the $C_{\max }$ and $A U C_{0-600}$ of griseofulvin were significantly decreased by pretreatment with chitosan, although changes in the plasma concentrationtime curves of griseofulvin by chitosan pretreatment were similar to those of indomethacin. This discrepancy between these parameters for indomethacin and griseofulvin may be explained by insufficient sampling time to calculate the true pharmacokinetic parameters. Other mechanisms for chitosan-induced delay in the absorption of griseofulvin may remain.

Gallaher et al. ${ }^{14)}$ reported that chitosan did not increase the intestinal content supernatant viscosity in rats, although chitosan is known to exhibit a substantial viscosity. They suggest that the cholesterol-lowering effect of chitosan is not associated with its viscosity. However, it is possible that pretreatment of chitosan affects the gastric emptying rate, which is one of the important factors to determine the absorption rate of drug, due to its viscosity. ${ }^{12,13)}$ On the other hand, Heading et $a{ }^{26)}$ have reported a significant relationship between the $T_{\max }$ of acetaminophen and the half time of gastric emptying following an oral administration of acetaminophen in humans, suggesting that acetaminophen absorption is de- pendent on the rate of gastric emptying. They note that acetaminophen $\left(\mathrm{p} K_{\mathrm{a}}\right.$ 9.5) unionized in both stomach and small intestine is absorbed rapidly from the small intestine due to its greater surface area. In the present study, chitosan had no effect on the plasma concentration-time profiles of acetaminophen, which is absorbed via a passive diffusion mechanism. We further examined the effect of chitosan on the plasma concentration-time profiles of the amino- $\beta$-lactam antibiotic cephalexin, which is actively absorbed from the small intestine via di-/tri-peptide transporter, PEPT1, expressed in the brush border membrane in humans and animals. ${ }^{27)}$ Expectedly, there was no significant difference in the plasma concentrations of cephalexin between vehicle- and chitosan-pretreated rats. It is therefore unlikely that the mechanism of chitosan-induced interaction in the absorption process is due to alterations of the gastric emptying rate.

It is recognized that the dissolution rate of a drug is often a rate-limiting step when the drug is given orally as a solid form. Coadministered drugs or foods might affect the gastrointestinal absorption of drugs with low solubility and high permeability such as indomethacin and griseofulvin by changing their solubility and dissolution rate in the gastrointestinal tract. For example, it is reported that coadministration of high-fat meals enhances the absorption of waterinsoluble drugs, griseofulvin, ${ }^{28)}$ danazol ${ }^{29)}$ and carbamazepine, ${ }^{30)}$ by increasing the dissolution rate of these drugs. It is also thought that the increased bioavailability of drugs in the presence of a high-fat meal is due to the increased secretion of bile salts, pancreatic juice and digestive enzymes by the high-fat meal. ${ }^{13)}$ There is an in vitro report indicating that the solubility and dissolution rate of griseofulvin increase with increasing the medium concentration of bile salts such as sodium taurocholate and sodium cholate. ${ }^{31)}$ Miyazaki et $a l{ }^{32)}$ have reported that the enhancement of the dissolution of indomethacin in the presence of bile acids, including sodium desoxycholate, sodium cholate, sodium glycocholate and sodium taurocholate, is due mainly to micellar solubilization. Based on these observations, it is considered that the prolonged $T_{\max }$ for indomethacin and griseofulvin in chitosan-pretreated rats may be caused by disruption in micelle formation due to the binding of bile acids to chitosan, leading to reduction of any solubilization effect by bile acids.

Chitosan acts as a weak anion exchange resin as well as the hypocholesterolemic agent cholestyramine, ${ }^{33)}$ which decreases cholesterol absorption and enhances the fecal elimination of bile acids and neutral sterols. ${ }^{34,35)}$ It is clinically known that the gastrointestinal absorption of anionic drugs such as aspirin, phenobarbital, phenylbutazone and warfarin are decreased by coadministration of cholestyramine. It is, therefore, considered that another possible explanation for chitosan-induced alteration in the absorption of indomethacin is the binding of anionic drugs to chitosan in the gastrointestinal tract, leading to modification of their physicochemical properties. To understand the mechanism of chitosan affecting the plasma concentration-time profiles of indomethacin after oral administration, we further examined its effect on the absorption profiles of indomethacin after administration of the solution formulation prepared with $1 \%$ polyoxyethylene (20) sorbitan monooleate solution in place of suspension. As a result, chitosan had no effect on the plasma concentration-time profile of indomethacin, indicat- 
ing that chitosan does not affect the gastrointestinal absorption of indomethacin as a solvent form, which is mainly absorbed via the passive diffusion mechanism. From these findings, it is likely that chitosan pretreatment modifies the dissolution process of indomethacin, and that the binding to chitosan molecules is not a cause of this interaction between chitosan and indomethacin.

The hypocholesterolemic effect of chitosan having a molecular weight of $70 \mathrm{kDa}$ is reportedly much stronger than that having a higher molecular weight $(<750 \mathrm{kDa})$. LeHoux and Grondin $^{36)}$ have demonstrated that chitosan of $750 \mathrm{kDa}$ partially blocks the increases in the plasma cholesterol levels provoked by sterol diet, whereas chitosan with $750 \mathrm{kDa}$ and $2000 \mathrm{kDa}$ showed no effect on the increase in the plasma cholesterol levels induced by a high sterol diet. Further studies are needed to evaluate whether the effect of chitosan on the drug absorption process is varied by its molecular weight and viscosity.

In conclusion, the present study suggests the possibility that chitosan interacts with water-insoluble drugs in the gastrointestinal absorption process due to inhibition of the solubilization effect of bile acids.

Acknowledgements The authors are extremely grateful to Sugiyama Drugs Co., Ltd. (Nagoya, Japan) for providing useful information regarding chitosan.

This study was supported in part by a Grant-in-Aid for Scientific Research (17590500) and a Grant-in-Aid of the Scientific Frontier Research Project of Meijo University from the Ministry of Education, Culture, Sports, Science and Technology of Japan.

\section{REFERENCES}

1) Furda I., "Aminopolysaccharides - Their Potential as Dietary Fiber," ed. by Furda I., Unconventional Sources of Dietary Fiber ACS Symposium Series, 1983, pp. 105-122.

2) Lee J. K., Kim S. U., Kim J. H., Biosci. Biotechnol. Biochem., 63 833-839 (1999)

3) Ylitalo R., Lehtinen S., Wuolijoki E., Ylitalo P., Lehtimaki T., Arzneim.-Forsch., 52, 1-7 (2002).

4) Bloch K., Berg B. N., Rittenberg D., J. Biol. Chem., 149, 511-517 (1943).

5) Heuman D. M., Hernandez C. R., Hylemon P. B., Kubaska W. M. Hartman C., Vlahcevic Z. R., Hepatology, 8, 358-365 (1988).

6) Gallo D. G., Bailey K. R., Sheffner A. L., Proc. Soc. Exp. Biol. Med., 120, 60-65 (1965).

7) Robinson D. S., Benjamin D. M., McCormack J. J., Clin. Pharmacol.
Ther, 12, 491-495 (1971).

8) Nauss J. L., Thompson J. L., Nagyvary J., Lipids, 18, 714-719 (1983).

9) Bates T. R., Gibaldi M., Kanig J. L., Nature (London), 210, 1331 1333 (1966).

10) Bates T. R., Gibaldi M., Kanig J. L., J. Pharm. Sci., 55, 191-199 (1966).

11) Bates T. R., Gibaldi M., Kanig J. L., J. Pharm. Sci., 55, 901-906 (1966).

12) Rowland M., Tozer T. N., "Clinical Pharmacokinetics," 2nd ed., Williams \& Wilkins, Philadelphia, 1989, pp. 113-130.

13) Fleisher D., Li C., Zhao Y., Pao L. H., Karim A., Clin. Pharmacokinet., 36, 233 -254 (1999).

14) Gallaher C. M., Munion J., Hesslink Jr. R., Wise J., Gallaher D. D., J. Nutr., 130, 2753-2759 (2000).

15) Razdan A., Pettersson D., Br. J. Nutr., 76, 387-397 (1996).

16) Apichartpichean R., Hasegawa T., Nadai M., Kuzuya T., Nabeshima T., J. Pharm. Pharmacol., 43, 262-269 (1991).

17) Tsunekawa Y., Hasegawa T., Nadai M., Takagi K., Nabeshima T., J. Pharm. Pharmacol., 44, 594-599 (1992).

18) Haghgoo S., Hasegawa T., Nadai M., Wang L., Ishigaki T., Miyamoto K., Nabeshima T., J. Pharm. Pharmacol., 47, 412-419 (1995).

19) Vudathala G. K., Rogers J. A., J. Pharm. Sci., 81, 1166-1169 (1992).

20) Sawamoto T., Kurosaki Y., Kimura T., Nakayama T., Biol. Pharm. Bull., 19, 77-82 (1996).

21) Brunner L. J., Bai S., J. Chromatogr. B, 732, 323-329 (1999).

22) Maezaki Y., Tsuji K., Nakagawa Y., Kawai Y., Akimoto M., Tsugita T. Takekawa W., Terada A., Hara H., Mitsuoka T., Biosci. Biotechnol. Biochem., 57, 1439-1444 (1993).

23) Wuolijoki E., Hirvela T., Ylitalo P., Methods Find. Exp. Clin. Pharmacol., 21, 357-361 (1999).

24) Gallaher D. D., Gallaher C. M., Mahrt G. J., Carr T. P., Hollingshead C. H., Hesslink Jr. R., Wise J., J. Am. College Nutr., 21, 428-433 (2002).

25) Gades M. D., Stern J. S., J. Am. Diet Assoc., 105, $72-77$ (2005).

26) Heading R. C., Nimmo J., Prescott L. F., Tothill P., Br. J. Pharmacol., 47, 415-421 (1973)

27) Tamai I., Tomizawa N., Takeuchi T., Nakayama K., Higashida H., Tsuji A., J. Pharmacol. Exp. Ther., 273, 26-31 (1995).

28) Palma R., Vidon N., Houin G., Pfeiffer A., Rongier M., Barre J., Bernier J. J., Eur. J. Clin. Pharmacol., 31, 319-325 (1986).

29) Charman W. N., Rogge M. C., Boddy A. W., Berger B. M., J. Clin. Pharmacol., 33, 381-386 (1993).

30) Levy R. H., Pitlick W. H., Troupin A. S., Green J. R., Neal J. M., Clin. Pharmacol. Ther., 17, 657-668 (1975).

31) De Smidt J. H., Offringa J. C. A., Crommelin D. J. A., J. Pharm. Sci., 80, 399-401 (1991).

32) Miyazaki S., Inoue H., Yamahira T., Nadai T., Chem. Pharm. Bull., 27, 2468-2472 (1979).

33) McNamara D. J., Davidson N. O., Samuel P., Ahrens E. H., J. Lipid Res., 21, 1058-1064 (1980).

34) Stanley M. M., Paul D., Gacke D., Murphy J., Gastroenterology, 65, 889-894 (1973).

35) Gallaher D. D., Franz P. M., J. Nutr., 120, 1320-1330 (1990).

36) LeHoux J.-G., Grondin F., Endocrinology, 132, 1078 -1084 (1993). 